\title{
CHANGES IN EMISSIVITY OF THE ELECTRODES FOR RESISTENCE SPOT WELDING DUE TO THEIR WEAR
}

\author{
${ }^{1}$ Lucie FOREJTOVÁ, ${ }^{2}$ Tomáš ZAVADIL, 'Ladislav KOLAŘíK, ${ }^{1}$ Marie KOLAŘíKOVÁ, ${ }^{3} J a n$ SOVA \\ ${ }^{1}$ Czech Technical University in Prague, Faculty of Mechanical Engineering, Prague, Czech Republic, EU, \\ Lucie.Forejtova@fs.cvut.cz \\ ${ }^{2}$ Czech Technical University in Prague, Faculty of Nuclear Sciences and Physical Engineering, Prague, \\ Czech Republic, EU \\ 3WORKSWELL, Prague, Czech Republic, EU, jan.sova@workswell.cz
}

https://doi.org/10.37904/metal.2019.855

\begin{abstract}
Resistance spot welding is one of the most used welding technologies for joining of thin, deep drawn steel sheets in automotive industry. The condition of electrodes may have significant impact on the resulting weld quality, therefore it is necessary to check the electrodes' wear that otherwise may cause creation of specific defects in the weld joints. One of the possibilities is utilization of infrared thermography. In order to perform the testing correctly it is essential to know the expected emissivity of the electrodes. This article deals with the changes in emissivity due to wear. It demonstrates that the emissivity of new electrodes is significantly different in comparison with worn electrodes. The biggest change is observed between the first and 25th weld. With increasing number of performed welds the emissivity drops slightly with increasing number of welds. The increased temperature caused significant drops when temperature is elevated up to $40{ }^{\circ} \mathrm{C}$, but it is virtually constant for temperatures above $40^{\circ} \mathrm{C}$. It concludes that a mean "operational emisivity of the electrodes operated at higher temperatures (i.e. $40^{\circ} \mathrm{C}+$ ) is a suitably accurate factor to be used during the weld inspection on defects.
\end{abstract}

Keywords: Automotive, resistance spot welding, thermography, ultrasonic testing

\section{INTRODUCTION}

Electrodes for resistance spot welding (RSW) have major impact on quality of the weld joint. Electrodes are a part of the welding machine's secondary circuit and they are in direct contact with welded sheets. Their main task is to bring welding current of very high intensity to the welding spot. It is also through them how the force for forging is transmitted. For that reason the electrodes need to be from a material with low electric resistivity (usually from $\mathrm{Cu}$ alloys), yet with good mechanical properties ( $\mathrm{Cr}$ alloying elements added).

Electrode wear as a result of RSW of steel sheets with surface coatings (mainly Zn coatings) is affected by many factors. Due to thermal, electrical and mechanical load (metallurgically as well - due to diffusion of the coating to the electrode's parent material) the effective electrode geometry is changed, the surface becomes more coarse, contact areas may be contaminated and electrode's parent material undergoes changes of mechanical and physical properties [1]. Metallurgically created coating is created on the contact area quickly and already after several first performed welds the conditions for current flow are significantly changed. That affects the general ability to create weld joints, their quality and process repeatability [1].

Number of performed weld joints is an important parameter for effective creation of structural RSW welds. It directly influences the electrode life and it is defined as the number of weld joints the electrode is able to produce with regular weld nugget (larger than critical size of the nugget, as defined by e.g. EN ISO 8166) [2]. Weld quality continually decreases with electrode wear - the weld nugget is smaller, nuggets are not symmetrical and at the end weld joints are not created at all [3]. For that reason it is necessary to be able to estimate expected electrode life for RSW based on their wear and ensure their effective use. 
In engineering practice, in order to prevent further wear of electrodes, the manufacturers (e.g. in automotive) usually adjust the electrode geometry by milling of the electrode faces. This process may be repeated several times before the electrode is scrapped permanently. It is usually performed preventively (after specific number of performed welds) and therefore with no relation to the real electrode wears (neither real nor estimated).

RSW electrodes therefore represent one of the least reliable parts of the RSW process and their replacement or preventive milling is common intervention to the manufacturing process. Additionally, electrode wear represents one of the common reasons for decrease in quality of performed welds, or it is a source of scrap rate of manufacture products.

Research performed at CTU in Prague (UST FS CVUT) aims to timely detection of excessive electrode wear for RSW by analysis of thermographic data. This contactless method for detection of electrode wear is joined with necessity of sufficiently accurate assessment of thermal radiation of the electrode tip. For that it is necessary to know the inherent thermal radiation of electrode tips and the reflected thermal radiation originating from the surrounding environment and especially from the surface of welded sheets. This information is important for determination of real thermal field on the welded surface [].

The goal of this article is to perform partial experimental measurement of change of emissivity as one of the thermographic data as a function of electrode wear and temperature.

\section{EXPERIMENT}

The experiment was based on measurement of change of emissivity $\varepsilon$ as a function of electrode wear (number of performed welds $N$ ) and electrode temperature T. Deep-drawn steel DC05+ZE (EN 10152) with electrolyte coated $\mathrm{Zn}$ with total thickness $\mathrm{h}=0.7 \mathrm{~mm}$ and coating thickness $4.5 \mu \mathrm{m}$ was used in this experiment. This steel is commonly used for car shells. Chemical composition and mechanical properties of DC05 steel are listed in Table 1 [1].

Table 1 Chemical composition and mechanical properties of DC05 steel

\begin{tabular}{|c|c|c|c|c|c|c|c|}
\hline C [\%] & Mn [\%] & P [\%] & S [\%] & Si [\%] & $\operatorname{Re}\left[\mathbf{N} / \mathbf{m m}^{2}\right]$ & $\mathbf{R m}\left[\mathbf{N} / \mathbf{m m}^{2}\right]$ & A $_{80}[\%]$ \\
\hline 0.06 & 0.35 & 0.025 & 0.02 & 0.02 & $\max .200$ & $270-330$ & 39 \\
\hline
\end{tabular}

Forged electrode tips for RSW 39D 1978-2 with clamping area diameter $\varnothing 16 \mathrm{~mm}$ and contact area diameter $\varnothing 5 \mathrm{~mm}$ from A2/2 - $\mathrm{CuCr} 1 \mathrm{Zr}$ were used (see Figure 1). Chemical composition of electrode tip was $98.98 \%$ $\mathrm{Cu}, 0.9 \% \mathrm{Cr}$ and $0.12 \% \mathrm{Zr}$ [1]. The experiment was monitored by thermographic camera FLIR T540.
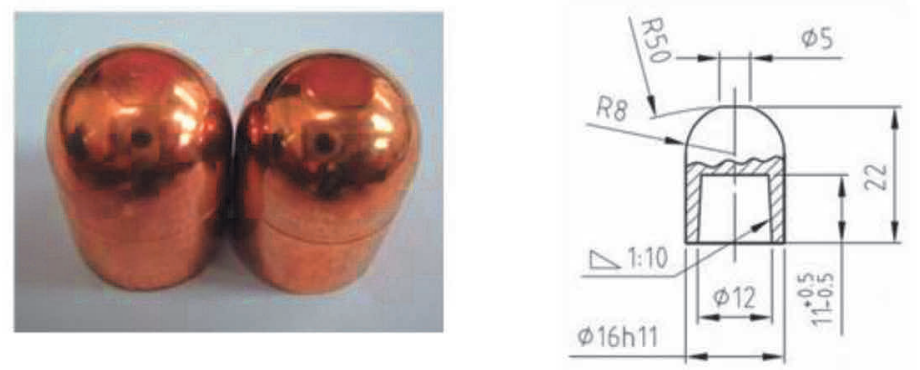

Figure 1 Image and a technical drawing of electrode tip type 39D 1978-2, Ø5 mm

Set of worn electrode tips with defined level of wear ( $\mathrm{N}$ performed welds) was created with the following welding parameters: $\mathrm{I}=6.5 \mathrm{kA}, \mathrm{P}=2 \mathrm{kN}$, ts $=200 \mathrm{~ms}$. These parameters were selected based on previous optimization process [1]. Each pair of electrode tips (top and bottom electrode tip) was created by performing $\mathrm{N}$ welds, where $N$ was selected as following: $N=\{10 ; 25 ; 50 ; 75 ; 100 ; 150 ; 200\}$ (see Figure 2). 


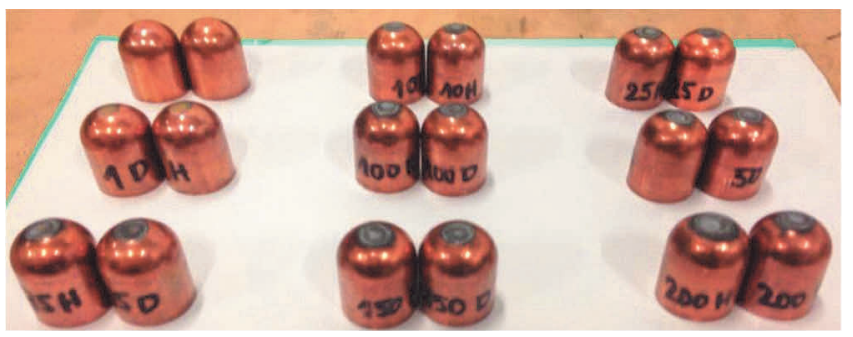

Figure 2 Pair of worn electrode tips used for the experiment

\subsection{Measurement of emissivity for new electrode tips}

Two electrode tips were placed on a sheet jig and together placed to the LE type furnace LAC, heated to the temperature of $90{ }^{\circ} \mathrm{C}$ and then naturally cooled to $40^{\circ} \mathrm{C}$. The cooling process was recorded by thermographic camera. By a K-type thermocouple attached to one of the electrodes the measured temperature by thermographic camera was compared to real temperature (measurement unit Ahlborn Almemo 5690). Recorded data were evaluated in FLIR Tools software (in accordance with methodology mentioned in ISO 18434-1) [4]. Emissivity was determined for all recorded temperatures and these data were used to create a trend of emissivity as a function of temperature (see Figure 3 - right).
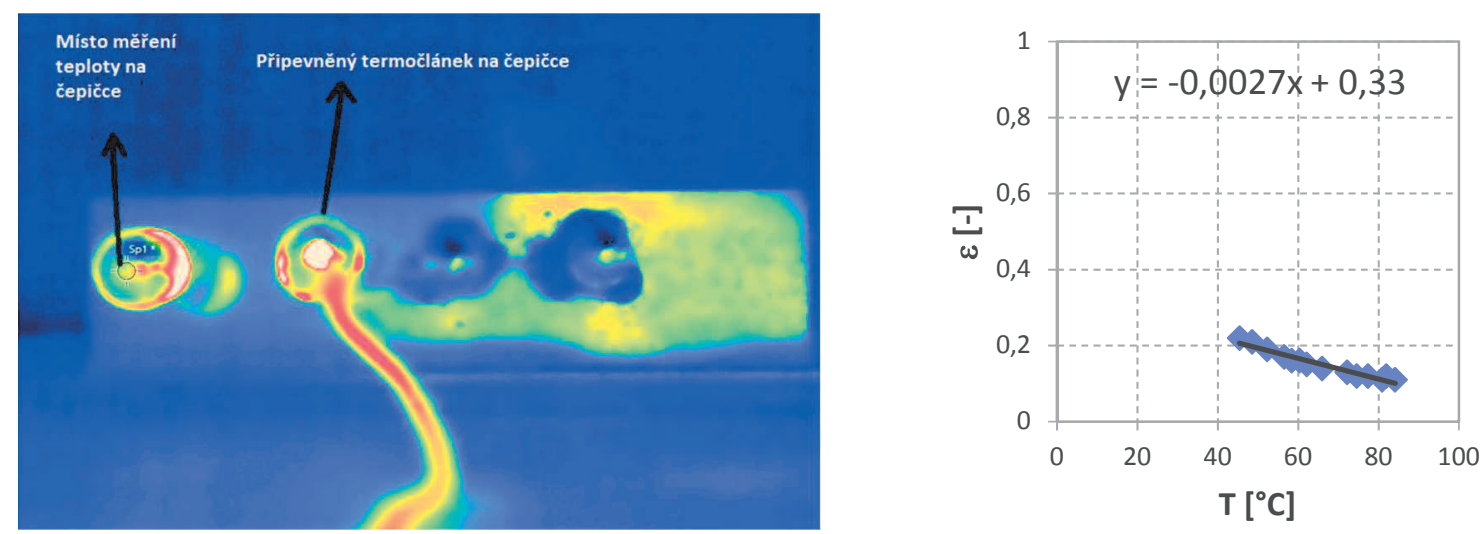

Figure 3 Principle of emissivity measurement on electrode tips and result of the measurement on new electrode tips

Figure 3-right shows that the emissivity for new electrodes is decreasing with increasing temperature from its original value of 0.2 for temperature of $40^{\circ} \mathrm{C}$ to its final value of 0.11 for temperature of $90^{\circ} \mathrm{C}$.

\subsection{Measurement of emissivity for worn electrode tips}

Procedure for measurement of emissivity for worn electrode tips was similar to measurement for new electrode tips, with the difference that the sheet jig was heated in the furnace on temperature of $150^{\circ} \mathrm{C}$. After extraction of the jig from the furnace the electrode tips were placed on the sheet jig and electrode tips were heated by heat transfer from the jig to the electrode tips till the temperature of electrode tips started to decrease again as measured by Ahlborn Almemo 5690. K-type thermocouple was attached to one of the electrodes in each pair and used the same as in the case of new electrode tips to assess their real temperature. Heating process was recorded from approximately $30^{\circ} \mathrm{C}$ to $90{ }^{\circ} \mathrm{C}$. With real ambient temperature of $18^{\circ} \mathrm{C}$ temperature measured by the camera was $20^{\circ} \mathrm{C}$ [5]. This approach proved to be more effective than direct heating because $\mathrm{Cu}$ is prone to oxidation at elevated temperatures and oxide layers may significantly affect surface conditions of electrode tips. By assessment of emissivity change by FLIR Tools software the emissivity as a function of temperature was determined. This process was performed for all electrodes, where each pair represented one N. 
Only temperatures from the interval $T \in<40^{\circ} ; 90^{\circ}>$ were used to evaluate the effect of temperature on emissivity of worn electrode tips. This is in agreement with ISO 18434-1 [4] according to which the difference between the ambient temperature and minimal recorded temperature should be at least $20^{\circ} \mathrm{C}$.

(a) $\mathrm{N}=\mathbf{2 5}$

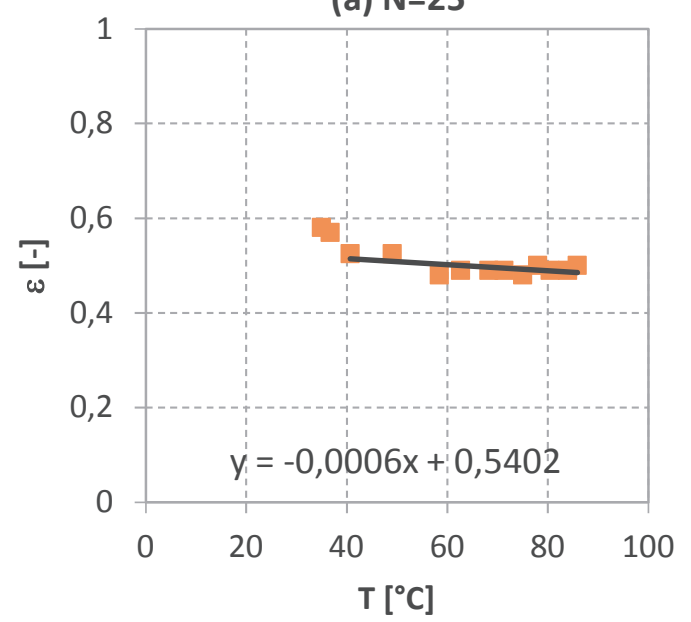

(c) $\mathrm{N}=75$

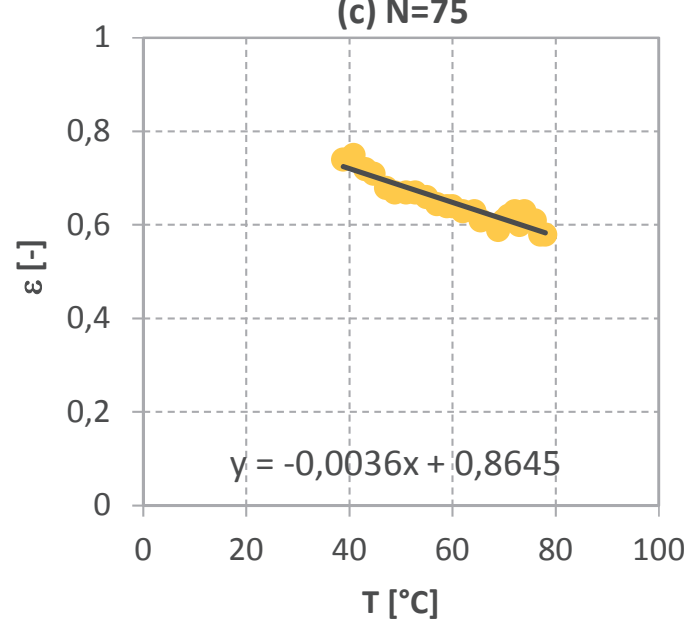

(e) $\mathrm{N}=150$

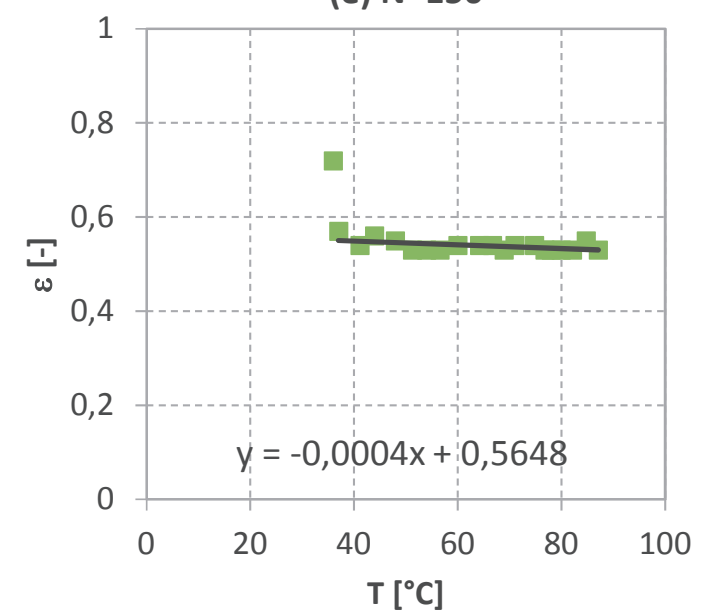

(b) $\mathrm{N}=50$

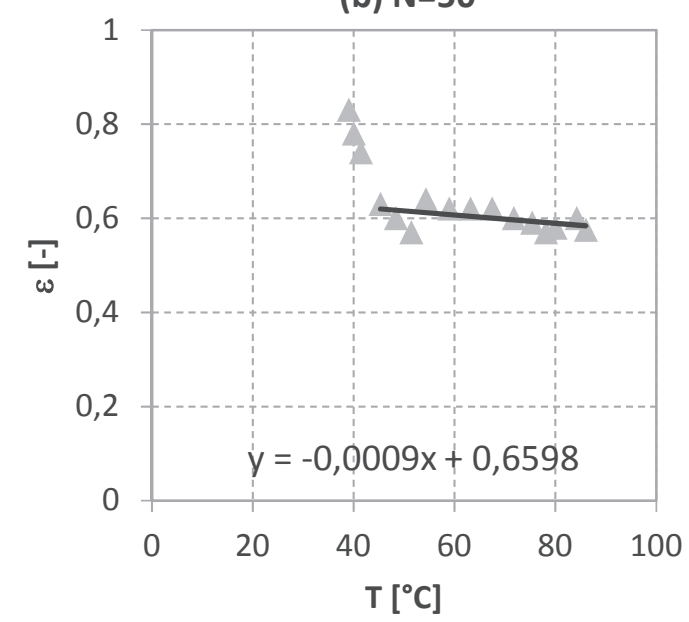

(d) $\mathrm{N}=\mathbf{1 0 0}$

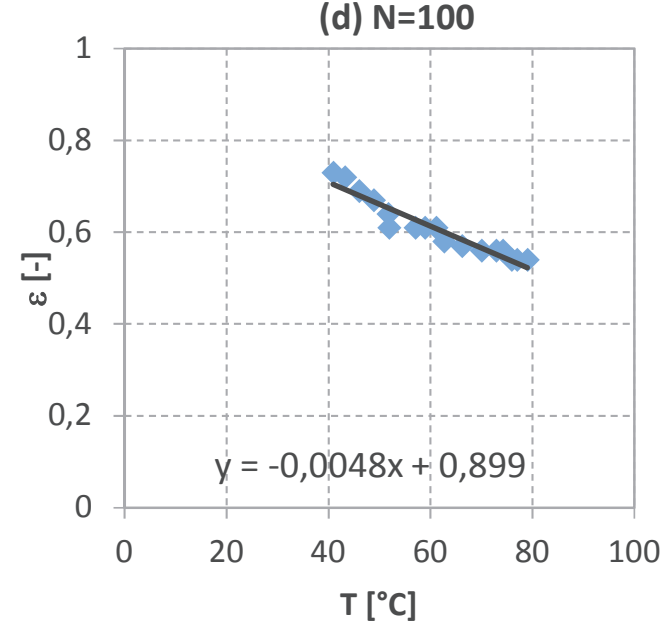

(f) $\mathrm{N}=\mathbf{2 0 0}$

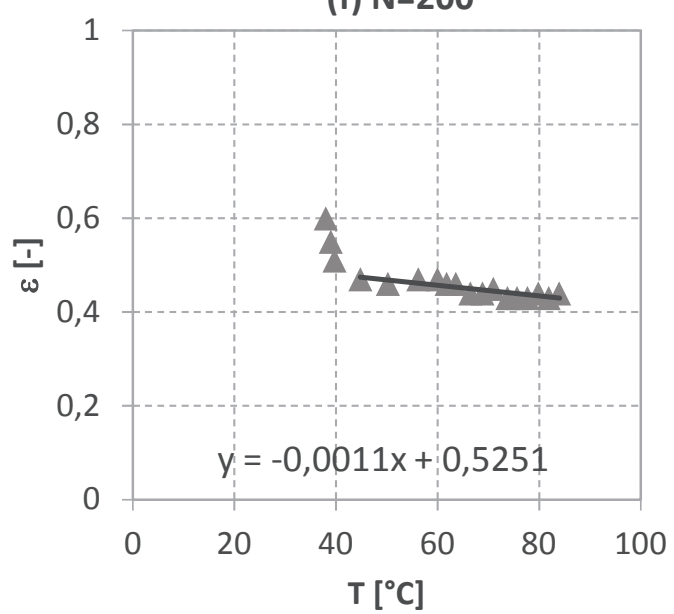

Figure 4 Emissivity $\varepsilon$ as a function of temperature $T$ for performance of $N=25(a), N=50$ (b), $N=75(c)$, $\mathrm{N}=100(\mathrm{~d}), \mathrm{N}=150(\mathrm{e})$ and $\mathrm{N}=200(\mathrm{f})$ welds 
In Figure 4(a) it is visible that emissivity of electrode tip is increased almost three times for $\mathrm{N}=25$ welds compared to new electrodes and it reached $\varepsilon=0.6$ for temperature $40^{\circ} \mathrm{C}$. Emissivity decreases towards $\varepsilon=$ 0.5 on higher temperatures.

In Figure 4(b), Figure 4(c), and Figure 4(d) similar trend may be observed. Regression curve is generally moving to higher values and emissivity of the electrode tips start from up to $\varepsilon=0.8$ for temperature of $40{ }^{\circ} \mathrm{C}$. Negative slope of the regression curve is increasing with number of performed welds $\mathrm{N}$ up to its maximum for $N=150$ then it drops again. For values above $N=150$ (when e.g. Škoda Auto mills the electrode faces) the emissivity decreases below $\varepsilon=0.5$, which is best visible in Figure 5 [6].

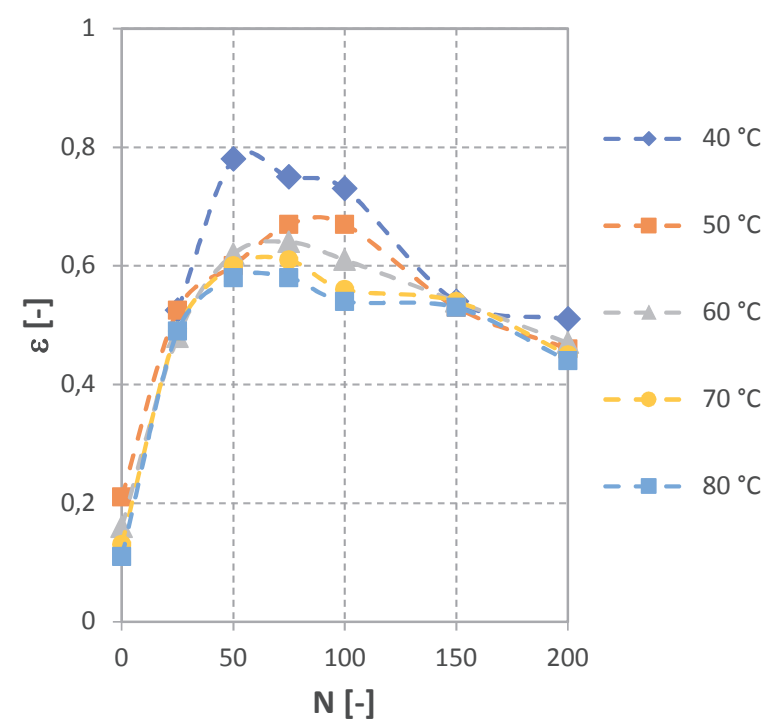

Figure 5 Emissivity as a function of electrode wear (number of performed welds $\mathrm{N}$ ) for various temperatures

\section{DISCUSSION}

It is obvious from the performed measurements that the emissivity is changing with number of performed welds (i.e. with wear), with abrupt change to higher values already after few first performed welds as visible in Figure 3, Figure 4 and Figure 5. This abrupt change is most likely caused by creation of alloyed layer with $\mathrm{Zn}$ coating on the effective contact area of the electrode tip caused by diffusion of $\mathrm{Zn}$ from deep-drawn sheet DC05. Further increase of emissivity in the interval of $\mathrm{N}=25$ and 75 is higher for lower temperatures, which might be caused by longer saturation time of the electrodes by $\mathrm{Zn}$ for lower temperatures than for the higher ones, which results in later stabilization of emissivity value [4 5].

Originally it was expected, that the emissivity is continually increasing with increasing electrode wear. Results from Figure 5, however, show that the increase is limited to only some extent and after reaching a critical value of performed welds $\mathrm{Nc}$ (for all temperatures $\mathrm{Nc}$ is in the interval $50<\mathrm{Nc}<75$ ) it decreases again.

Change of emissivity $\Delta \varepsilon$ was decreasing with increasing temperature, i.e. it is less pronounced for higher temperatures (for easy to observe example see Figure 5, change of emissivity between $\mathrm{N}=100$ and $\mathrm{N}=150$ ). It is also visible that higher temperatures reach nominally lower maximal emissivity and variation of emissivity for different electrode wear $\mathrm{N}$ is smaller as observed in Figure 4(e), Figure 4(f) and Figure 5.

For temperatures $70{ }^{\circ} \mathrm{C}$ and $80^{\circ} \mathrm{C}$ and the interval of performed welds from $\mathrm{N}=25$ to $\mathrm{N}=150$ the emissivity varied in only a narrow range $(\varepsilon=0.49-0.61)$. Despite changes are relatively small (except the abrupt change compared to new electrodes), the emissivity in engineering practice cannot be considered as constant.

For electrode wear reaching $\mathrm{N}=150$ welds (when the electrode faces are usually milled), the emissivity dropped below $\varepsilon=0.5$ and for $N=200$ it continued to decrease the more the higher was the temperature. Low 
level of emissivity is caused by change of material properties of the electrode tips due to excessive wear, that is for higher temperatures occurring earlier (i.e. for lower $\mathrm{N}$ ).

Electrode wear is closely associated with change of roughness, change of electrode geometry and change of contact area. Measurement of roughness may therefore provide important comparative measurement for detection of electrode wear via change of emissivity. That is one of the partial research steps the UST FS CVUT is partaking at the moment [5].

\section{CONCLUSION}

The goal of the article was to define the relation of emissivity of the RSW electrode tips on the electrode wear. For this purpose an experiment was performed on 7 pairs of electrodes with various levels of electrode wear (number of performed welds) and heated to various temperatures.

It was concluded that the emissivity is increasing with increased electrode wear only to some extent. After abrupt increase of emissivity after performing first few welds the emissivity is reaching to its maximal value between 50 and 75 performed welds and for higher number of performed welds it decreases again no matter the temperature of the electrode tip. The temperature affects the dynamics of emissivity change and with increasing temperature this change is smaller, which is probably caused by faster saturation of electrode tips with alloying elements. It may be therefore assumed, that observing of emissivity change dynamics may help with estimation of real electrode wear for effective use of electrode tips before their milling and/or scrapping.

The electrode wear is closely related with change of roughness, change of electrode geometry and change of contact area. Continuation of the research performed on UST FS CVUT is now aiming to use the information about change of roughness for more accurate description of emissivity changes based on electrode wear and it shall be a subject to future articles.

\section{ACKNOWLEDGEMENTS}

\section{This research was been supported by the project TRIO No. FV10757 „Thermovision system for non- destructive testing of weld joints", financed by MPO ČR.}

\section{REFERENCES}

[1] FOREJTOVÁ, L., ZAVADIL, T., KOLAŘíK, M., KOLAŘíKOVÁ, M. Defect detection of resistence spot welds used in automotive industry by non-destructive testing, In METAL 2018: 27th International Conference on Metallurgy and Materials. Ostrava: TANGER, 2018, pp. 688 - 693.

[2] ISO 8166:2003 Resistance welding - Procedure for the evaluation of the life of spot welding electrodes using constant machine settings . 10/2004-03/2016.

[3] SHAPOVALOV, E.V., GALAGAN, R.M., KLISHCHAR, F.S., ZAPARA, V.I. Modern methods and means of nondestructive control of a welded connection performed by contact spot welding (review), E.O. Paton NAS of Ukraine. 03680, Kiev-150, st. Bozhenko: Scientific and technical section, 2013.

[4] ISO 18434-1:2008 Condition monitoring and diagnostics of machines - Thermography - Part 1: General procedures

[5] PEŤKOVÁ, V. and SVOBODA, J. Thermodiagnostics. Košice, Vienala s.r.o. 2016. p. 310.

[6] DVORAK, M. and PILVOUSEK, T. Materials used for bodywork, Company documents - ŠKODA Auto a.s., 2014. 